\title{
An Exploratory Study of Male Adolescent Sexuality in Zimbabwe: The Case of Adolescents in Kuwadzana Extension, Harare
}

\author{
Sandra Bhatasara, Tafadzwa Chevo, and Talent Changadeya \\ Sociology Department, University of Zimbabwe, P.O. Box MP167, Mount Pleasant, Harare, Zimbabwe \\ Correspondence should be addressed to Tafadzwa Chevo; tafadzwachevo@hotmail.com
}

Received 8 April 2013; Revised 28 August 2013; Accepted 6 September 2013

Academic Editor: Kaushik Bose

Copyright (C) 2013 Sandra Bhatasara et al. This is an open access article distributed under the Creative Commons Attribution License, which permits unrestricted use, distribution, and reproduction in any medium, provided the original work is properly cited.

\begin{abstract}
Although young people in Zimbabwe are becoming sexually active at a very early age, there is no unified body of knowledge on how they regard sex and construct sexuality and relationships. In many circumstances adolescence sexual agency is denied and silenced. This study explored adolescents' discourses on sexuality, factors affecting adolescent sexuality, and sexual health. Fusing a social constructionist standpoint and an active view of agency, we argue that the way male adolescents perceive and experience sexuality and construct sexual identities is mediated by the sociocultural context in which they live in and their own agency. Although adolescents are mistakenly regarded as sexual innocents by society, we argue that male adolescents are active social agents in constructing their own sexual realities and identities. At the same time, dominant structural and interactional factors have a bearing on how male adolescents experience and generate sexuality.
\end{abstract}

\section{Introduction}

This study explores empirically adolescents' construction of sexuality. According to Nyanzi [1] sexuality is constructed as the domain exclusive to adults with preconditions of physical and social maturity. Thus, notions of child sexuality are often viewed as taboo, antithetical, nonissues, or even dangerous and cause for moral panic. Such perceptions of "unknowledgeable or ill-informed adolescents" and "high-risk adolescents" are rife in the literature on youth and HIV/AIDS [2]. Adult sexual cultures and religious and moral discourses are deployed or implicated in positioning adolescent sexuality as taboo. Putting sexuality and children together remains problematic and morally troubling regardless of policy efforts to change this [3]. As noted by Renold [4], underlying this trouble are familiar ideologies that associate school-going learners with sexual innocence which creates the myth of an asexual child who must be protected from corrupting sexual information, producing a regulatory mechanism through which morality, sexuality, and young people at school are framed. Longstanding tropes of sexual innocence position the child as an object of concern, thwarting sexual curiosity
[5]. In spite of such narrow conceptualizations of children, a number of studies demonstrate that adolescents are active sexual beings. Against representations that associate children with sexual innocence, this study examined adolescents' discourses on notions of sexuality as well as their sexual health as it has been demonstrated that their needs are different from those of adults. The focus of the study is particularly on boys because they are implicated in literature as having an active role in sexuality as evidenced by the fact that the burden of negative sexual consequences usually falls disproportionately on females [6].

\section{Background}

Sexual activities among adolescents are reported to be increasing worldwide [7]. Research in sub-Saharan Africa has documented high and increasing premarital sexual activities among adolescents. It is generally recognized that African adolescents are sexually active and suffer from consequences of routine unsafe sexual practices such as teenage parenthood, illegal abortions, and sexually transmitted diseases (STDs) including HIV/AIDS. Schaalma and Kaaya [8] note 
that a review of school based studies of adolescent sexual behavior in sub-Saharan Africa supports the observation that significant proportions of adolescents are sexually active by the time they are in their midteens with many having had sexual intercourse with two or more partners and condoms being rarely used routinely.

With reference to Zimbabwe, the demography is typical of a developing country with nearly 45 per cent of the population below the age of 13 and adolescents constituting approximately 36 per cent of the total population [9]. The Intercensual Demographic Survey 2008 report highlighted that Zimbabwe's population is relatively young with over 62 per cent being 24 years and below. Adolescents in Zimbabwe face unprecedented challenges; among them are sexually transmitted infections (STIs) including HIV/AIDS, high levels of teenage pregnancies, unsafe abortions, and limited access to sexual and reproductive health rights [10]. The 2005/6 Zimbabwe Demographic Health Survey (ZDHS) reported a high rate of teenage pregnancies as high as 21 per cent, for the 15 to 19 age group. Adolescent fertility was reported to be higher in rural (120 per 1000 girls) than urban (70 per 1000 girls) areas. The onset of sexual activity generally begins before marriage with close to 40 per cent of female adolescents being already mothers by the time they are 19 years old [9]. In addition to this, there is unavailability of youth friendly Sexual and Reproductive Health services (SRH) and adequate related information contributing to young people engaging in sexual behaviors that put them at risk of HIV infection.

In sub-Saharan Africa, as highlighted above, adolescents are engaging in premarital sexual activities. According to Aggleton and Rivers [11], regionally, the age of sexual debut for adolescents is falling. However, existing literature about this theme has largely concentrated on the adult population in the developing world [12]. Izugbara [12] notes that scholarly interrogations of adolescent sex, sexuality, and relationships in developing areas are hardly available. If available, these are framed within the confines of sex education and considerable attention has been paid to the dangers of heterosexual unprotected sex such as adolescent pregnancy and sexually transmitted infections.

Interest in adolescent's agency and sociocultural contexts of their sexual discourses, behavior, and practices has proliferated recently but the irony is that very little of this debate is informed by what adolescents themselves say about sex, sexuality, and their experiences of them [13]. Usually, adolescents are viewed as a healthy stratum of the population and schools as peaceful arenas where students pursue their academic goals. Children and youth are rigidly compartmentalized, defined in opposition to adults, and seen as being in need of adult protection [14]. Against this background, the objectives of this study are

(a) to investigate male adolescents discourses on sexual relationships and sexuality,

(b) to identify factors affecting male adolescents sexuality,

(c) to determine sexual health related concerns of male adolescents.
Given the paucity of information that exists on how adolescent boys construct their sexuality in Zimbabwe, this research will expand on existing body of knowledge on sexuality. Although the social and historical construction of sexuality perspective is not new in both anthropology and sociology, our understanding is that it has not been widely applied in examining adolescent sexualities in Zimbabwe. Our research is framed in contrast to research that addresses children as relatively passive desexualized beings, focusing on their dependence on adults, their innocence, and their need for protection [5]. The study employs a qualitative methodology that captures nuanced adolescent experiences hence departing from the quantitative approaches used in demographic and baseline surveys which measure and quantify sexual behavior. According to Chikovore et al. [15] research on sexual and reproductive health in Zimbabwe has chiefly employed quantitative approaches. They argue that studies however need to be complemented with other approaches more appropriate for addressing complexities in sexual matters and for generating experiences and meaning. In this paper we also go beyond the sexual and reproductive health approach by capturing adolescents' discourses.

\section{Theoretical Framework}

In reconfiguring the predominantly marginalized and supposedly passive, Zimbabwean male adolescent, we utilize social constructionist theory and the concept of agency to analyze adolescent discourses on sexuality. The focus of social constructionist theory is to uncover the ways in which individuals and groups participate in the creation of their perceived reality. It postulates that what we perceive as reality is shaped through a system of sociocultural and interpersonal processes [16]. Social constructionist theory thus emphasizes that sexuality is a social construction. Vance [17] calls for a social constructionist approach to sexuality that would examine the range of behavior, ideology, and subjective meaning among groups and would view the body, its sensations, and functions as potentials which are mediated by culture.

This approach can thus be a useful framework in analyzing adolescent sexuality as it locates the individual/adolescent within a sociocultural milieu; that is, adolescents learn about sexual behaviors and how to interpret sexual behavior within a social context. It places greater emphasis on location within social structure as the primary force influencing the social construction of reality, including conceptions and experiences of sexuality. Social constructionist theory therefore places more emphasis on the individual's role in constructing reality being guided by prevalent discourses in their societies and cultures [18]. Sexuality is thus influenced by social norms, culture, and personal experiences.

The utility of social constructionist theory can also be found in its emphasis on meaning attached to sexual acts. According to Vance [17] physically identical sexual acts may have different social and personal meanings depending on how they are defined and understood in their different cultures and historical periods. This approach enables one to focus on how adolescents define situations and thereby 
construct realities in contexts in which they live. Social constructionist theory explores an evolving set of meanings that are continuously created from people's interactions and the capability of adolescents in creating and recreating roles from different situations. Through social constructionist theory researchers can look for diverse meanings of sexuality within and between social groups. Besides influencing the way individuals define and act on their behaviors, socio-historical constructions also organize and give meaning to collective sexual experience through, for instance, constructions of sexual identity, definitions, ideologies, and regulations [17]. In this regard, a more capacious view of children, alert to their agency, can provide fresh perspectives on the salience of gender and sexuality [5]. By combining a social constructionist perspective and the concept of agency, we are theorizing male adolescents as active agents situated within a specific sociocultural context. As Bhana [19] agued, children's exercise of agency is socially embedded.

\section{The Construction of Sexuality}

This section of the study discusses adolescent sexuality within current and prevailing literature. The first section will present literature on sexuality in general while the second section dwells on literature specifically on adolescent sexuality.

4.1. Human Sexuality. Sexuality is broadly defined as the range of behaviour associated with the ideals, desires, practices, and identities linked with sex. Literature on sexuality highlights that the dominant and often recognized form of sexuality is heterosexuality. According to Mahcera [20] in Africa heterosexuality is a more privileged status than homosexuality. This usually frames how sexuality is viewed in society, often informing definitions of female and male sexuality. Hamm (1995) cited by Jaffray [21] argues that definitions of female and male sexuality aside from cultural variations are overwhelmingly directed by the ideology of heterosexuality. This leads to other forms of sexuality, that is, homosexuality being construed as deviant [21].

Scholarly interrogations on sexuality increasingly highlight the social nature of sexuality. They point out that sexuality is a product of cultural contexts rather than biological drives and how these drives are mediated by culture. According to Caplan [22] sexuality is not biologically given; it is socially and culturally constructed and in constant state of flux. A social constructionist approach to sexuality that sees biological potentials as essentially mediated by culture has been invoked [17]. Research on the social construction of sexuality points to the differences in sexual practices within and across cultures. Arnfred [23] points to the existence of multiple sexualities existing in societies. Literature thus largely calls for the attachment of meaning and reading of sexuality in its context.

A lot has also been written about the power dynamics inherent in human sexuality. Weeks [24] alludes to the view of human sexuality as being rife with contestation, politics, and enactments of control and power. Nyanzi [1] notes that although sexuality is a private matter the sexual terrain is also very political. Foucault [25] points to the concept of governmentality of sexuality in which conduct of sexuality is guided by social control. Such control mechanisms are apparent in the processes of socialization in society in which behavior is imparted and normalized. Rose et al. (2009) cited in Tamale [26] argue that the main aim of socialization is the shaping of individuals with a certain mode of self-reflection and certain civilized techniques of self-government. This is also highlighted through the policing of female sexuality in Africa and the repressions of homosexuality sentiments in Zimbabwe and other African countries.

4.2. Adolescent Sexuality. Adolescent sexual behavior, particularly in sub-Saharan Africa, has been put under the spotlight in light of the AIDS pandemic which is disproportionately affecting adolescent age groups with a particular toll on girls than boys $[6,10]$. Literature generally highlights the precarious position adolescents face with regard to their sexuality and poor reproductive health outcomes. Several researches that have been done across Africa usually paint a gloomy picture about adolescents in sub-Saharan Africa as facing a host of sexual and reproductive health problems; among them are STIs, unwanted pregnancies, unsafe abortions, lack of contraception, sexual abuse, and rape. Studies indicate that sexual debut in Southern Africa is coming too early with unsafe sexual practices among adolescents especially inconsistent condom use and multiple partners persisting despite awareness and programmes to change behavior [11]. Insufficient knowledge concerning reproduction, sexuality, and contraceptives and inadequate family planning services have been cited as the main reasons why adolescents face challenges in managing their sexuality.

Although much has been documented about the knowledge, attitudes, and practices of adolescents it must be noted that much of the scholarship is mainly on children aged 15-19 years of age $[12,27]$. Izugbara [12] notes that there are still relatively limited research and evidence on the sexual and reproductive knowledge of children and younger adolescents aged 10-14 years of age. WHO [27] notes that older adolescents aged 15-19 years have drawn the lion's share of the attention while the special needs and concerns of younger adolescents aged 10-14 years (some of whom are already sexually active) have been relatively neglected. The focus upon younger children under the age of ten is partly due to children's assumed incompetence around abstract sexual health issues [19]. Adolescents are regarded as children and ignorant by society and even by researchers, making them an uninteresting social group to study. The core concern here is that excessive sexual knowledge is dangerous because it suggests the erosion of innocence [5]. However, children's sexual agency has been expressed in a number of studies. For example, studies conducted by Bhana $[3,5,19,28]$ observed that children are active agents in giving meaning to sex, sexuality, and even HIV and AIDS. According to Bhana and Epstein, [29] sex play remains an important currency in young African children's cultural worlds despite the adult wish to deny it.

Another theme that runs through adolescent sexuality literature is the disparity in HIV infection levels between men and women in many parts of Africa especially in adolescent 
age groups where many more girls than boys are infected. HIV prevalence is almost three times higher among women aged 15-24 than among men [10]. Various researches note that age mixing in sexual relationships between older men and adolescent girls (sugar daddies) is on the rise. These asymmetrical relationships reportedly involve an exchange of money and gifts for sexual favours. These are reported to be characterized by gender power imbalances and limited negotiating power for the girls involved. The motivations for younger girls have mainly been construed as being motivated by economic gain; hence, as Masvawure [30] notes, most of the literature on asymmetrical relationships narrowly construes age mixing relationships as economic strategies for survival.

Attempts have also been made to articulate the difference in adolescent sexuality between urban and rural adolescents with regard to their sexual practices. Urban adolescents are reported to be more liberal in their sexual attitudes than rural adolescents. Peltzer [31] in his research among adolescents in rural and urban South Africa notes that urban adolescents reported that they had significantly more often petted, masturbated, had anal and oral sex, and practiced kissing and cuddling more frequently while rural adolescents more frequently practiced penetrative sexual intercourse. According to Peltzer [31], among rural adolescents in Zimbabwe few reported ever having masturbated. Relationships appear to be less stable among urban adolescents than rural adolescents due to a number of reasons.

The ways adolescents construct sexuality has also been interrogated within adolescent studies on sexuality. Harrison et al. [32] cited by Lesch and Bremrigde [33] exposed a common narrative of sexual control, pressure, or in some instances even violence by male adolescents on their female partners in heterosexual relationships. Literature also shows that adolescent sexuality has predominantly been constructed or understood as impulsive and justified through biology and desire. Lesch and Bremridge [33] note that the construction of male sexuality as a difficult to control physiological drive has frequently been adopted and validated in research on male sexuality. Concerning unsafe sexual behavior amongst South African youth, Eaton et al. [34] found it common for young people to justify unsafe sex by means of a discourse of biology and sexual urges. However, although research on adolescent sexuality highlights issues of deception, coercion, intimidation, and violence, other studies have shown that both men and women may be victims of sexual coercion in heterosexual relationships [35, 36]. According to Shefer et al. [37] adolescents often find themselves in situations in which issues of consent, coercion, and ambiguous sexual negations are at play.

Attention has also been given to the nature of research that sought to document knowledge, attitudes, and practices of adolescents. Hence, Izugbara [13] notes that traditional psychology based health behavior models have tended to dominate explanations of adolescent views and commentaries on sex and sexuality. A major criticism of these models is that they ignore the critical sociocultural context that shapes human sexual notions and behavior and the agency of human beings. As a result, within adolescent sexuality studies there is an increasing call to utilize the qualitative research methodology that is flexible and can capture the accounts of the youths [38].

\section{Materials and Methods}

5.1. Research Design. The research is designed under a qualitative paradigm. Gibson and Brown [39] define qualitative research as an array of attitudes toward and strategies for conducting inquiry that are aimed at discerning how human beings understand, experience, interpret, and produce the social world. According to Marshall and Rossman [40] qualitative research is pragmatic, interpretive, and grounded in the living experiences of people.

A qualitative paradigm suits the goals of this study that are to solicit how adolescents perceive their sexuality and factors affecting their sexuality. It is consistent with the theoretical framework (social constructionism) which is primarily concerned with elucidating the processes by which people come to describe, explain, and otherwise account for the world in which they live; hence, it becomes important to listen to the participants own voices in studying adolescent boys perspectives on sexuality. Qualitative methods such as in-depth interviews were better suited to explore and study meanings, experiences, and processes and provided male adolescents with the opportunity to give accounts of their experiences in their own words. Its methods are thus consistent with social constructionist theory.

5.2. Sampling Strategies. The study utilized convenience sampling to select the study site and purposive availability, snowballing, and self-selection sampling techniques to select respondents. According to Gibson and Brown [39] in purposive sampling, selection of participants, setting, and other sampling units are criterion based. The sample units are chosen because they have particular features or characteristics that will enable a detailed exploration and understanding of the central puzzles that the researcher wishes to study. In essence, the sampling techniques used in this study enabled us to obtain the appropriate respondents who provided sufficient data to meet our research objectives.

5.3. Study Site. Kuwadzana Extension is a formally planned, low-income, high-density area on the western edge of the city of Harare. It is $30 \mathrm{~km}$ away from the city centre. It is a housing project which began in the early 1980s, shortly after the independence of Zimbabwe, and continued in fits and starts in phases [41, 42]. The average monthly income for the area is 616 US Dollars with an average household size of 6 [43]. The site was selected because it provided a population frame that was appropriate for the researchers to recruit and to capitalize on the familiarity the researchers have on the neighborhood as well as the prior networks that existed with some of the adolescent participants. Hence for the researchers this was particularly advantageous given that sex and sexual behavior are sensitive topics; hence there could be difficulties in enlisting participants. Kuwadzana is the largest of Harare's high-density areas (HDAs) in Harare 
and is believed to be broadly representative of the HDAs as it is so large and incorporates different phases developed under various housing policy regimes.

5.4. Sample. The study population comprised 16-19 in-school adolescents. The World Health Organization defines adolescence as the period between the ages 10 and 19 years with further categorizations into three phases: early adolescence $10-$ 13 years, middle adolescence $14-15$ years, and late adolescence 16-19 years. Adolescence can also be conceptualized as the period of transition from childhood to adulthood describing the development to sexual maturity and to psychological and relative economic independence. The sample is comprised of 40 adolescent boys from the 16-19 age group, a number that was adequate in providing sufficient data required for the study. A key informant who is the Guidance and Counseling teacher at one of the local schools was also selected to participate in the study because of her vantage point in discussing such topics with adolescents. The sample was small; hence it does not claim to be representative of the whole population of Kuwadzana Extension or adolescents in Zimbabwe in general.

5.5. Strategies of Data Collection. In-depth interviews were the principal method used in gathering data. In-depth interviewing is a qualitative research technique that involves conducting intensive individual interviews with a small number of respondents to explore their perspectives on a particular idea. However, because of the usually small samples of indepth interviews it can be difficult to make generalizations about the whole population [40]. Key informant interviewing was also utilized with a Guidance and Counseling teacher at one of the local schools. Marshall [44] sees a key informant as an expert source of information and because of their personal skills or position within a society is able to provide more information and a deeper insight into what is going on around them.

Since the study was concerned with soliciting the perceptions of adolescents on sexuality as well as their needs, indepth interviewing was suitable as it could best answer the objectives of the study. It was compatible with the theoretical inclinations of the study which was concerned with how people participate in the construction of their reality. All the interviews were carried out using an interview schedule containing open-ended questions. This gave the researchers room to explore emerging issues during the interviews.

5.6. Data Analysis. Qualitative data analysis is the search for general statements about relationships and underlying themes [40]. It involves using generalized themes to look at the relationships between components of data. According to Gibson and Brown [39] thematic analysis refers to the process of analyzing data according to commonalities, relationships, and differences across a data set. In this study, themes were derived from the study objectives. One of the key features of thematic analysis is the examination of commonalities in the data (ibid). Accordingly, through coding and labeling, the data was organized in order to identify data that fell

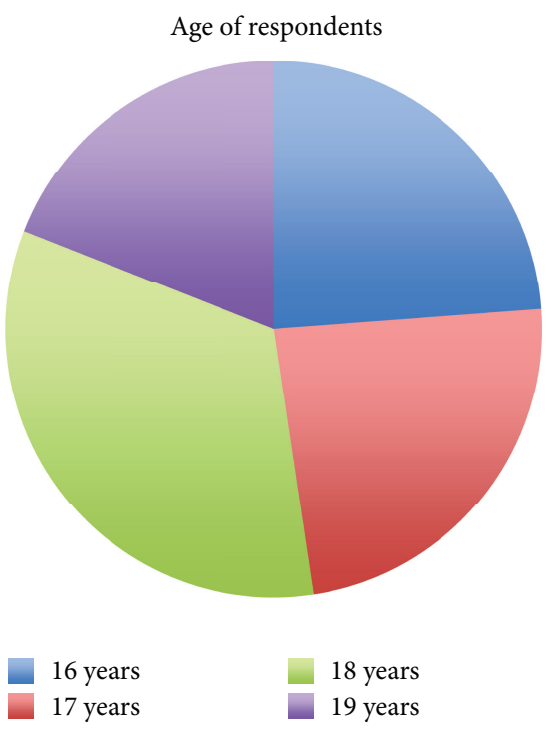

Figure 1: Age of respondents.

under the various themes identified from the study objectives. To generate socioeconomic characteristics of the respondents from the open-ended questions, data was reorganized and then coded after data collection.

5.7. Ethical Considerations. Conducting research with young people is fraught with practical and ethical pitfalls (McIlwaine and Datta, 2006). Sexuality is a sensitive issue in many cultures. According to Lie [45] approaching issues of sexuality and reproductive health involve careful consideration of how to address people, for instance, how to ensure that an individual's integrity is protected and how to show respect for existing social values and existing subcultural values. We sought consent from all of the participants before they were interviewed. They were briefed about the research topic and informed that they were not obliged in any way to answer any questions that they felt uncomfortable with. They were also informed that they were free to withdraw from the interview at any time of the research. Participants were also assured of the confidentiality of the research and that the findings would be used for academic purposes only and their real names would not be used. Permission was also sought from guardians and parents of those who were below the legal age of majority (18 years).

5.8. Findings. This section presents the key findings of the study thematically.

5.9. Social Differentiation of Male Adolescents in the Study. As highlighted earlier, all of the adolescents who participated in our study reside in Kuwadzana Extension, which is a low-income, high-density residential area. The majority of the participants were aged 18 (shown in Figure 1) and all of them reside with a guardian or parent(s) (Figure 2). With regard to educational levels, the majority of them were high school students, currently studying for their advanced level 


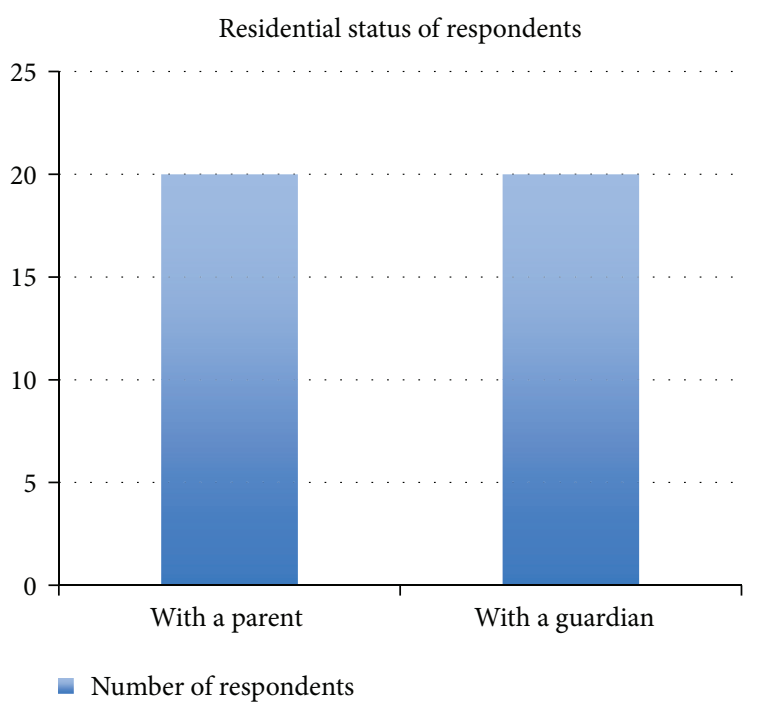

Figure 2: Residence status.

Relationship status of respondents

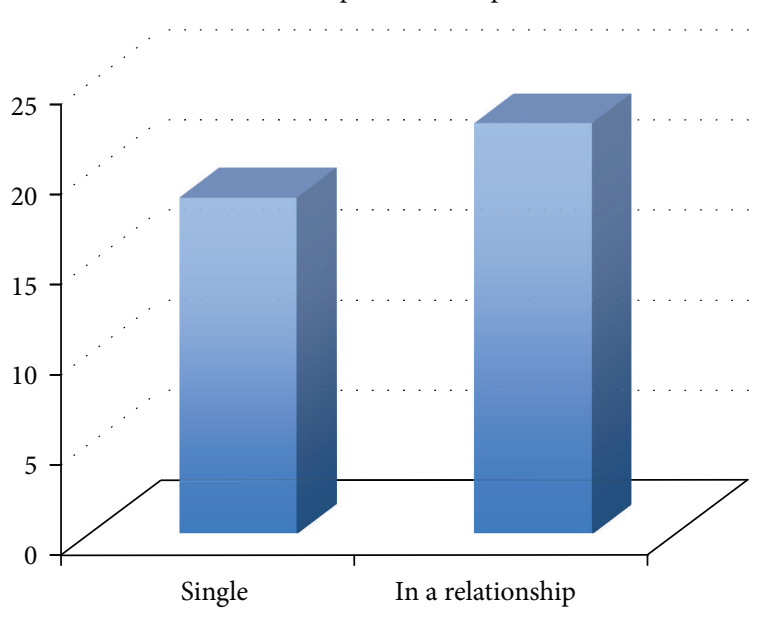

- Number of respondents

Figure 3: Relationship status.

certificates. The rest were in secondary school. When asked about relationship status, 55\% said they are currently in a relationship (Figures 3 and 4).

5.10. Discourses on Sexual Relationships. The majority of the adolescents interviewed reported concern about the nature of relationships with girlfriends. Respondents perceived adolescent girls as being careless and loose in relationships as well as easy to sleep with. The boys voiced concern about girls being unfaithful and at times deserting them particularly for the prospect of financial benefits in other relationships. Girls were accused of putting relationships at risk because of greediness and love for money. One respondent remarked "anogona kumhanya neshamwari yako, achimhanya newe nekuda cash." (she can manage to go out with both you and your friend simply to get money). The general consensus in

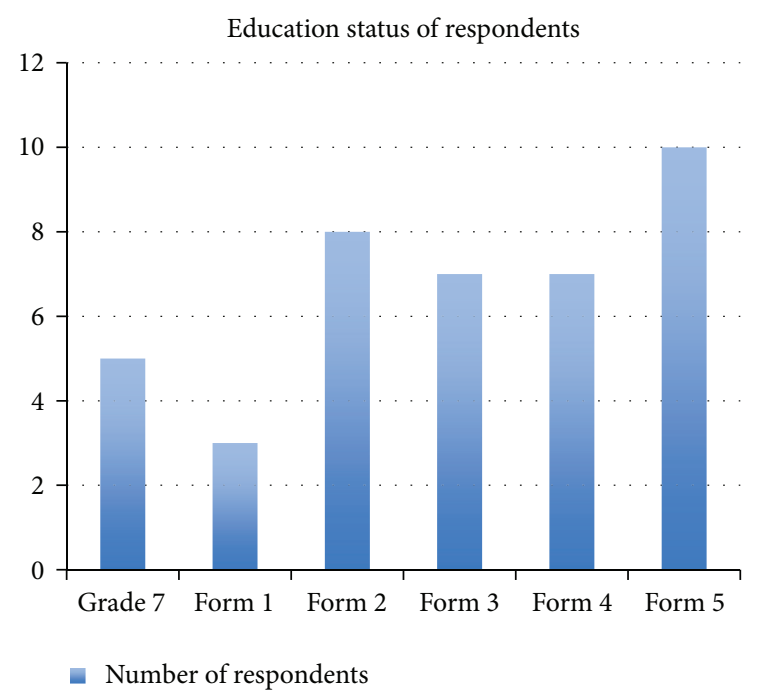

FIgURE 4: Highest level of education attained.

most of the responses was that girls in relationships were failing to decline sex because of love for monetary gains. Girls were also accused of cheating on their boyfriends with commuter omnibus drivers who were considered risky partners.

Some male respondents reported concern about being pressured into sex by girls. According to a key informant, boys actually complain about how girls pressure them into sex shortly after getting into relationships. Another respondent alluded to the fact that girls are too permissive to sexual advances and not decisive in fending them off. According to a boy interviewed girls actually enjoy being sexually intimate and long for sex. Referring to girls he had this to say "vana vamazuvano vanoda kubatwa" (these girls like to be fondled and to be intimate). Girls were also reported to refuse to use protection during intercourse on the pretext that they were not prostitutes or that it was less pleasurable. Some adolescents were of the notion that one must have sex with his partner and failure to do so highlights that the relationship would not be fruitful. One respondent was quoted saying "ukamhanya nemusikana, mukarambana usina kurara naye hauna zvawaita" (if you are in a relationship, if it ends without you sleeping with her, you have lost). Male adolescents thus perceived girls as putting them and their relationships in jeopardy and that relationships and love were based on sexual intimacy.

Some respondents expressed concern about not being able to take care of their girlfriends financially. Financial stability was thus perceived by most boys as being vital in maintaining relationships. Respondents felt that failure to deliver financially might actually lead to one being unfaithful and putting the other at risk as one respondent put it: "ndikasamu supplier avotsvaga kumwe achimhanya neni and undercover relationships are dangerous" (if I do not look after her she will cheat on me resulting in risky multiple partnership). They pointed to the cost of buying airtime as well as other financial obligations expected of them. One respondent pointed out that while parents provided for them 
financially they were oblivious of the fact that they had other obligations of maintaining their own relationships. One respondent perceived the financial obligations incurred in a relationship as being tantamount to getting a prostitute: "gen'a harizvikete kuti kutenga airtime kunozongofanana nekubhadhara hure" (some guys do not realize that buying air time ultimately amounts to engaging a prostitute).

Those interviewed felt that parents and teachers were not doing much in advising adolescents in their relationships. Most of the respondents were concerned by how parents imposed themselves in their sexual relationships. Respondents reported that parents and teachers should advise them about sexual activity and relationships rather than dictate to them. The boys felt that parents and guardians fail to appreciate that times have changed; hence they should adapt to the nature of sexual relationships that are now prevalent rather than being old fashioned: "ngavafambirane nenguva kwete kuti usadaro usadaro ngavapinde maari kwete kuva opposite" (they should live in the present not to tell you do not it; instead they should give me money and be more supportive). Adolescent boys perceive parents as not being open when talking about issues of sexuality. The respondents highlighted that although they were not willing to talk about sexual activity they already knew about it: "kana vakasatitaurira tagara tinozviziva" (even if they do not tell us we already know).

5.11. Sexual Encounters of Size and Sexual Satisfaction. Meanings attached to sexual performance emerged from respondents. There were suggestions that sexual performance symbolized a "real man" and one should satisfy his girlfriend sexually. A respondent alluded to the fact that sometimes girls mock those they perceive to be incapable of satisfying them sexually by demeaning their manhood. Girls were reported to mock them saying "muface uyu haagone kubata haana dhiri" (this guy is incapable of sexually satisfying). Usually adolescent boys are reported to brag about their sexual prowess and duration they can last during intercourse. Boys in the study associated good sex skills with the ability to last long in the sexual act. Premature ejaculation was thus a major concern, was demeaned and considered embarrassing, and resembled weakness.

Some adolescent boys reported concern about the size of their genitals. Those with small genitals were said to be ridiculed and perceived to be less potent sexually and unable to satisfy their partners while those with genitals considered being the ideal were perceived to be sexually potent and able to satisfy sexually during intercourse. One participant referring to those with small penises commented "kana unediki unosekwa" (if you have a small penis you are ridiculed). A big penis was thus viewed as a symbol of sexual strength and thought to be admired by girls. Some boys were reported to take mugondorosi (herbs) that are thought to enhance their penis sizes. Some reported frustration with girlfriends as they sought to be adventurous and engaged in some sexual practices that girls considered inappropriate. Some guys were reported to demand oral sex from their girlfriends and it was reported as a popular phenomenon among some boys.
5.12. Pornography, Peer Pressure, Pocket Size, and Parental Influences. Sources were adolescents who obtain information about sexuality issues that affect their perceptions and attitudes on sexuality. Respondents reported that the media was the main outlet of information where they leant about sex and relationships through films and music videos. It was highlighted that most boys try to imitate what they consume from the media. The consumption of pornographic material was reported to be very high in schools usually via mobile phone internet. One respondent commented "mafirimu ane ma notes akaipa manje" (films contain sexual tutorial skills). Some highlighted how music videos aroused sexual feelings usually through dance moves and type of dress worn. One respondent commented "matambiro a Ciarra anokonzeresa Mudhara" (the way Ciarra dances is sexually provocative) referring to the singer's dance moves as sexually provocative.

Respondents also reported peer influence as affecting decision making on issues relating to sexuality. Peer groups were reported to be a hive where adolescent boys discussed sexuality issues as well as boasting about sexual conquests. When quizzed why sexual conquests were important the majority of the boys said that this was because of prestige among peers as one boy put it "genia rinoda sugar nekukoreswa" (they want social recognition and prestige). One respondent highlighted that most of the narratives told were fabrications to gain social recognition but some try to live up to those narratives usually putting their sexual health at risk. Those who do not live up to the standards of the group are usually ridiculed and put under pressure and taunted for being cowards. Some peers were reported to influence others to engage in risky behaviors.

Respondents also reported economic circumstances as having a bearing on sexuality. Respondents highlighted that most adolescents who were unemployed and no longer went to school usually indulged in substance abuse and alcoholism that usually influenced them to practice unprotected sex and have multiple partners especially when drunk or high. Respondents suggested idleness of some adolescents due to lack of economic prospects as prompting them to chase girls as they have nothing else to do, usually leading to early pregnancies: "gen'a rinogara mu bridge harina zvimwe zvekuita kunze kwekutsvaga mabhebhi nekuputa mbanje" (those who are unemployed have nothing to do but chasing girls and smoking marijuana). Lack of knowledge and embarrassment reportedly deterred adolescent boys from seeking treatment for sexual health. Another respondent reported that it was difficult to convince a girl to go for HIV testing because she will be financially better. One respondent reported a phenomenon were guys who are financially stable refuse to use condoms: "vanenge vane cash havadi kushandisa ma condom, anenge achida kupinda akadaro, hanzi ndoda kukakaurisa" (those with money refuse to use condoms because they want to fix girls).

Ignorance and denial were cited during interviews as affecting sexual activity and behavior as well as risk perception. It was highlighted that some adolescent boys were aware of the consequences of having multiple partners and not using protection yet they continued to do so because of a carefree attitude about the consequences. A key informant pointed out 
that adolescent boys usually could not contemplate that what has happened to a friend can also befall them.

Respondents highlighted that parents should discuss openly with their children issues of sexuality. It was pointed out that failure to talk and inform boys about the dangers of sexual activity and how to mitigate them resulted in adolescents seeking information from media and peers. Lack of parental guidance and supervision was usually linked to poor sexual behavioral outcomes as adolescents are faced with conflicting messages from media and peers. Respondents reported that those with relaxed parental supervision had more opportunities to indulge in adolescent sexual intercourse. Adolescents reported frustration as well. For example, all the boys were living with either parent(s) or guardians; hence they have no privacy or rooms to be sexually intimate. Those boys with absentee parents or guardians were the envy of some of the boys. They were reported to be able to spend the whole day with a girl, a phenomena widely termed "kuvharira" (having base with some referring to their houses as lodges).

5.13. Sexual Health Concerns. Respondents expressed the need for parental guidance. It was reported that there must be open communication between parents and children on sexuality issues. Adolescents interviewed felt that parents were reluctant to talk openly about issues of love, sex, and relationships. They pointed out that usually mothers and girls were the ones who usually could discuss issues of sexuality, but rarely with boys. Some were however reluctant to speak about sexual activity with parents or guardians but cited immediate family members like brothers and sisters as ideal to advise them about sexuality issues. It was pointed out that parents should share their experiences as they had experienced such situations before; hence they are in a better position to offer advice.

Some respondents reported the need for accurate information about sexual activity. During interviews it was reported that the main sources of information were the media and peers with a few acknowledging acquiring information from parents or school sex education. It was highlighted during interviews that much of the information discussed with peers was not practical as highlighted by one respondent who said "rimwe team rinotaura zvinhu kuti rikoreswe, zvizhinji zvacho $i$ bhaiz" (most of the things said by peers are fabrications to give a false picture of prowess or heroism). A key informant interviewed pointed out that unless adolescents are taught at school they have poor or misleading knowledge about sexuality. Another respondent expressed the need for practical demonstrations in sexual education rather than just raw information. He alluded to the visual impact of videos, films, and pictures so they could understand better.

Adolescents need treatment for sexual health diseases in clinics to be affordable. A key informant interviewed noted that prices demanded at local clinics in Kuwadzana were a deterrent for adolescents seeking treatment. It is not that it is not that affordable, but many boys do not have access to such money even though it is not much. It was highlighted that it was very difficult for boys to ask for such money from parents without being questioned on their intentions. Easy access to condoms was also cited as problematic. During interviews accounts were narrated of some adolescents getting expired condoms from friends because they had no reliable sources to access condoms coupled with shyness to purchase condoms over the counter in shops. Lack of privacy at home was also cited as a deterrent factor preventing boys from keeping condoms hence when they wanted some they have to ask from friends. Adolescents are also concerned about early treatment for sexual diseases at clinics and hospitals rather than trying to seek treatment amongst themselves. Some boys were reported to seek help and treatment from friends to cure syphilis.

\section{Discussion}

This section discusses the research findings in light of existing literature, theory, and concepts. Mahcera [20] argues that in Africa male and female sexualities have been patterned by cultural definitions of masculinities and femininities. Hence, it can be argued that there is a close link between sexuality and masculinity in Africa. According to Connell [46] the term masculinity signifies a collective gender identity and not a natural attribute. It is socially constructed, fluid resulting in diverse forms across different times and contexts, and is mediated by sociocultural position, age, and other factors. He further notes that masculinity also defines how boys and men should behave, be treated, dress, and appear and what attitudes and qualities they should have. Such definitions have influences on the construction of sexuality within a society. It is our argument that the behavior and attitudes of boys are consistent with traditional forms of heterosexual masculinity and that sexuality of adolescent boys in the study is mediated by prevalent discourses of masculinity which have been noted to be socially constructed [20].

Connected to the representation of masculinity among these boys is sexual performance, and prowess is perceived to be critical in the boys' sexual practices and their construction of sexuality. Boys reported how important it was to be sexually active and powerful in relationships regardless of the socioeconomic context they exist in (such as the context in which HIV and AIDS are highly prevalent). Duration during intercourse was highlighted to be important and a source of pride; hence premature ejaculation was widely ridiculed and undesirable. Connell [46] notes that notions of masculinity are also closely associated with male virility, sexuality, and sexual performance. Sex for men is thus constructed as encompassing male virility, size of penis, and assumed potency in bed. Ratele [47] notes that in many parts if not all of postcolonial Africa, a significant theme of being a man revolves around sex. He further observes that nearly everywhere in the world sex is closely associated with our sexual partners, sexual appeal of our partners, the size of our penis, the claims we make about our sexual stamina, and how virile we are.

Meanings attached to the adolescent male body are essential in the construction of masculinity. Our findings reveal how some adolescent boys are concerned about the size of their penises. As highlighted in the study a small penis is 
a source of ridicule and shame. Contrary to biological determinism, this is so because a big penis is socially constructed as demonstrating sexual potency and ability to fulfill a girl. Izugbara [12] observed how prevailing codes of sexuality and sexual conduct in contemporary Nigeria are socially produced and fed by oppressive patriarchal subjectivities and ideologies among them penis-centred (i.e., they glorify and idolize traditional imageries of masculinity and male sexual prowess and encourage the objectification of women and their bodies). We argue that pressure to pursue sex in relationships also highlights influences of hegemonic discourses of male masculinity. Some adolescents in the study regard sex as an important aspect of relationships and something that must be pursued. It was generally agreed that one must have sex in a relationship before it is terminated for it to be labeled a success. Such notions are usually informed by social expectations of how males should behave sexually. The findings underscore that notions of sexuality and how adolescent boys perceive themselves are widely framed and located within the wider discourses of masculinity; hence, male adolescent sexuality is a social construction.

Silberschimdt [48] alludes to the view that masculinity worldwide has increasingly been constructed from wage earning power. Our study results highlight that boys in the study conform to traditional gender roles in negotiating relationships, as they are concerned about financially maintaining relationships. From the narratives of some of the boys in the study it can be noted that boys are expected to take the breadwinner role in relationships whilst girls were regarded as predominantly materialistic and too demanding. The boys are actually anxious about desertion that results if one fails to provide financially in a relationship. Boys' financial obligations in relationships are premised on existing traits of masculinity, which define the male as the one who fends for the family. This subscribes to expectations of males as providers. Pattman [49] also highlights from his studies in Botswana, Kenya, Rwanda, South Africa, Tanzania, Zambia, and Zimbabwe that boys were expected not only to "propose love" but also to be economic providers in heterosexual relations. In this regard, sexuality is premised on the notion of prevailing ideas of male social roles in relationships. The pressure to provide might thus be explained by aligning to the socially constructed roles of men and women in society (expectations of males as providers). Such expectations can thus be located within the social milieu in which adolescent boys live in and are socialized into.

This study argues that male adolescents construct, celebrate, and venerate their sexuality as hegemonic as such they do not appreciate female agency in sexual encounters. Female coercion, pressure, or suggestions on nonuse of condoms during sexual encounters is perceived negatively. Such an approach resonates with wider societal ideologies on femininities and masculinities in Zimbabwe. Thus, any form of female agency in heterosexual relationships challenges or "troubles" these boys. Notions of active masculinities and passive femininities are entrenched such that female coercion or pressure is "immoral" and wayward. Pattman [49] also found that boys were constructed as initiators of heterosexual relations through "proposing love" (including displays of sexual interest). Thus, female sexual agency is often denied in that young women are not expected to initiate or actively participate in sex but rather to let it happen to them [50]. Here we can note how male adolescents also display misogynistic and derogatory tendencies as part of creating and maintaining their sexuality when they regard girls as "loose", "greedy," and "careless."

In relation to the above, Arnfred [23] also points out that although women are expected to provide sex, it is unacceptable for them to initiate it. Such notions give weight to assertions by Arnfred [23] that in African contexts, a culture of silence assumed by women indicates a socially accepted behavioral constraint dictating that women reserve modesty and discretion in sexual relations while men are constructed as sexually unrestrained, confident, and forthright. Attempts to move into an initiating role can have serious negative consequences for them, with the assumption being that they are sexually experienced, and have an experience that is reserved for men (ibid). Such notions of adolescent boy's views on sexuality can be argued to arise from widely accepted concepts of masculinity. Boy's views in our study are thus derived from the sociocultural milieu and prevailing discourses about masculinity. By subscribing to such notions it can be argued that boys' views are being framed by masculine and feminine definitions of culturally prescribed behavior for males and females with ideas about femininity being associated with passivity while masculinity is associated with authority and domination [23]. As Martino [18] argues, their perceptions are being guided by prevalent discourses in their culture.

On the other hand, besides denial of female sexual agency, boys framed the pressure they get from their girlfriends in terms of sexual coercion. Subtle forms of coercion can also be noticed when girls ridicule and demean boys about poor sexual performance. Thus, although literature highlights sexual coercion and violence in adolescent heterosexual relationships as predominantly perpetuated against females by males, issues of coercion in heterosexual relationships are complex.

It can be argued that adolescent sexuality does not occur in a vacuum but is rather mediated by the context of everyday interaction with their environment. Responses from boys in the study point to the various influences that shape meanings and sexual attitudes of adolescents. Their sexual behavior and practices are framed in relation to peers, media, and economic circumstances. The media (television, music, and internet) and peers have become important parts of a repertoire of ideas and practices adolescents replicate. About peer groups, Valentine [51] is of the view that youth have to position himself or herself in relation to both adult and peer cultures. In terms of the media, adolescents are bombarded with media messages, which may save to reinforce inflexible gender and sexual roles. Adolescents observe several aspects of sexuality such as gender roles, affection and intimacy, erotic behavior, and family life. Ultimately, the media has important implications on adolescent sexuality as sex encounters in the media are erroneously presented as spontaneous, romantic, and risk free, with use of contraception and contraction of sexually transmitted infections rare. Therefore, social institutions not only give meanings to sexual acts but also provide sexual scripts to the male adolescents. 
Parent to child communication regarding sexuality is predominantly characterized by silence. Boys in the study point out that when parents talk about sexuality issues this is usually with girls but rarely with boys. In the absence of such talk adolescent boys usually end up getting such information, which is often inaccurate and ambiguous from the media or peers. It seems that parents feel that girls are the ones in need of immediate sexual information and talk because of the negative consequences such as teenage pregnancy that are usually blamed on the girls' behavior. According to boys interviewed such talk usually occurs between mothers and girls with the father virtually absent all the time. Such lack of talk to adolescent boys about sex might leave them vulnerable. The culture of silence might be explained by the fact that sexuality discourse in Africa still remains taboo and if parents could not discuss the subject with their parents, then it is most likely that they may feel embarrassed or uncomfortable discussing sexual messages with their own children.

It is interesting to note that most adolescents interviewed felt that parents should openly speak to them about sexuality. However, although adolescent boys expressed willingness to discuss sexuality matters with parents they were against notions of adults controlling their sexuality. Nyanzi [1] comments that many adults have difficulty in acknowledging adolescents as sexual beings and therefore adolescents' sexuality is viewed as something that must be controlled and restricted. Most boys felt that parents should adopt an advisory role rather than reprimand them. Most of the boys seemed to resent the imposition of parents in their relationships as well. This is not surprising if one heeds to Van den Bergh's [52] observation that in an increasingly urban context, adolescents' sexual relationships seem to be more and more regulated by adolescents themselves unlike when it was the concern of the society.

\section{Conclusion}

This study highlights the significant ways adolescents understand and construct sex, sexuality, and sexual health in relation to their own experiences, discourses, and the sociocultural environment. Study findings point out to the influences of popular discourses on masculinities, gender relations, male sexuality, and sexual expectations whilst recognizing adolescents' agency and interactional dynamics in constructing sexual reality. We conclude that efforts to deal with and understand adolescent sexuality must appreciate individual interpretations and the social and cultural environments in which adolescents are situated as these shape adolescents' sexual realities and may reinforce risky sexual behavior.

\section{Acronyms}

AIDS: Acquired immune-deficiency syndrome

HDA: High-density areas

HIV: Human immune-deficiency virus

ICPD: International Conference on Population and Development

SRH: Sexual and reproductive health

STD: Sexuality transmitted diseases
STI: $\quad$ Sexually transmitted infection

UNAIDS: Joint United Nations Programme on HIV/AIDS

UNFPA: United Nations Population Fund

WHO: World Health Organization

ZDHS: Zimbabwe Demographic and Health Survey.

\section{References}

[1] S. Nyanzi, "Unpacking the (govern) mentality of African sexualities," in Sexualities in Africa: A Reader, S. Tamale, Ed., pp. 477-501, 2011.

[2] P. Aggleton and I. Warwick, "Young people, sexuality, Hiv and Aids education," in Aids and Adolescents, L. Sherr, Ed., pp. 2436, Harwood Academic Press, Amsterdam, The Netherlands, 1997.

[3] D. Bhana, "Parental views of morality and sexuality and them implications for South African moral education," Journal of Moral Education, vol. 42, no. 1, pp. 114-128, 2013.

[4] E. Renold, Girls, Boys and Junior Sexualities, Routledge/Falmer, London, UK, 2005.

[5] D. Bhana, "Childhood sexuality and rights in the context of HIV/AIDS," Culture, Health and Sexuality, vol. 9, no. 3, pp. 309324, 2007.

[6] N. Luke, "Age and economic asymmetries in the sexual relationships of adolescent girls in sub-Saharan Africa," Studies in Family Planning, vol. 34, no. 2, pp. 67-86, 2003.

[7] A. Seme and D. Wirtu, "Premarital sexual practice among school adolescents in Nekemte Town, East Wollega," Ethiopian Journal of Health Development, vol. 22, no. 2, pp. 167-117, 2008.

[8] H. Schaalma and S. F. Kaaya, "Health education and the promotion of reproductive health: theory and evidence-based development and diffusion of interventions Programmes," in Promoting Adolescent Sexual and Reproductive Health in East and Southern Africa, Sweden, Nordiska Afrikainstitutet, K.-I. Klepp, A. J. Flisher, and S. F. Kaaya, Eds., pp. 56-75, HRSC Press, 2008.

[9] Center for Reproductive Law and Policy Child and Law Foundation, State of Denial: Adolescent Reproductive Rights in Zimbabwe, 2002.

[10] UNFPA Zimbabwe, Adolescent Sexual and Reproductive Health, 2011.

[11] P. J. Aggleton and K. Rivers, "Behavioural interventions for adolescents," in Preventing HIV Infection in Developing Countries, L. Gibney, R. DiClemente, and S. Vermund, Eds., Kluwer/Plenum Press, New York, NY, USA, 1999.

[12] C. Izugbara, "Notions of sex, sexuality and relationships among adolescent boys in rural southeastern Nigeria," Sex Education: Sexuality, Society and Learning, vol. 4, pp. 63-79, 2004.

[13] C. O. Izugbara, "The socio-cultural context of adolescents' notions of sex and sexuality in rural south-eastern Nigeria," Sexualities, vol. 8, no. 5, pp. 600-617, 2005.

[14] C. McIlwaine and K. Datta, "Endangered youth? Youth, gender and sexualities in urban Botswana," Gender, Place and Culture, vol. 11, no. 4, pp. 483-512, 2004.

[15] J. Chikovore, L. Nystrom, G. Lindmark, and B. M. Ahlberg, "Denial and violence: paradoxes in men's perspectives to premarital sex and pregnancy in Zimbabwe," African Sociological Review, vol. 7, no. 1, pp. 53-72, 2003.

[16] P. L. Berger and T. Luckman, The Social Construction of Reality, Anchor, Garden City, NY, USA, 1966. 
[17] C. S. Vance, "Anthropology rediscovers sexuality: a theoretical comment," Social Science and Medicine, vol. 33, no. 8, pp. 875884, 1991.

[18] M. I. Martino, The social construction of sexuality: personal meaning, perceptions of sexual experiences and female sexuality in Puerto Rico [Ph.D. thesis], Virginia Institute and State University, 1997.

[19] D. Bhana, "Beyond stigma? Young children's responses to HIV and AIDS," Culture, Health and Sexuality, vol. 10, no. 7, pp. 725$738,2008$.

[20] M. Mahcera, "Opening a can of worms: a debate on Female sexuality in the lecture theatre," in Re-Thinking Sexualities in Africa, S. Arnfred, Ed., pp. 157-172, 2004.

[21] P. Jaffray, Heterosexuality: Fuelling or Fighting HIV/AIDS Pandemic, Africa Regional Sexuality Resource Centre, University of Fort Hare, Eastern Cape, South Africa, 2006, http://www.arsrc .org/downloads/uhsss/jaffray.pdf.

[22] P. Caplan, The Cultural Construction of Sexuality, Tavistock Press, London, 1986.

[23] S. Arnfred, "Sexuality in Africa: tales and Silences," in ReThinking Sexualities in Africa, S. Arnfred, Ed., pp. 59-78, Nordiska Afrikainstitutet, Uppsala, Sweden, 2004.

[24] J. Weeks, Sexuality and Its Discontents: Meanings, Myths and Modern Sexualities, Routledge and Kegan Paul, London, UK, 1985.

[25] M. Foucault, "Governmentality," Ideology and Consciousness, vol. 5, pp. 5-21, 1979.

[26] S. Tamale, African Sexualities: A Reader, Fahamu/Pambazuka, Oxford, UK, 2011.

[27] WHO, "The sexual and reproductive health of young adolescents in developing Countries: Reviewing the evidence, identifying research gaps, and moving the agenda," 2011, http://www .who.int/reproductivehealth/en/.

[28] D. Bhana, “'AIDS is rape!” gender and sexuality in children's responses to HIV and AIDS," Social Science and Medicine, vol. 69, no. 4, pp. 596-603, 2009.

[29] D. Bhana and D. Epstein, "'I don"t want to catch it". Boys, girls and sexualities in an HIV/AIDS environment," Gender and Education, vol. 19, no. 1, pp. 109-125, 2007.

[30] T. Masvawure, “"I just need to be flashy on campus": female students and transactional sex at a university in Zimbabwe," Culture, Health and Sexuality, vol. 12, no. 8, pp. 857-870, 2010.

[31] K. Peltzer, "Sexuality among adolescents in rural and urban South Africa," Review of Sociology, vol. 37, pp. 189-199, 2006.

[32] A. Harrison, N. Xaba, P. Kunene, and N. Ntuli, "Understanding Young Women's risk for HIV/AIDS. Adolescent sexuality and vulnerability in Kwazulu-Natal," Society in Transition, vol. 32, no. 1, pp. 69-77, 2001.

[33] E. Lesch and C. Bremridge, "Safe sex and constructions of young male sexuality in one Western Cape community," South African Review of Sociology, vol. 37, no. 2, pp. 128-142, 2006.

[34] L. Eaton, A. J. Flisher, and L. E. Aaro, "Unsafe sexual behaviour in South African youth," Social Science and Medicine, vol. 56, no. 1, pp. 149-165, 2003.

[35] C. Macleod, "The "causes" of teenage pregnancy: review of South African research-part 2," South African Journal of Psychology, vol. 29, no. 1, pp. 8-16, 1999.

[36] Lovelife, The 2001 National Survey of South African Youth, African Strategic Research Corporation and the Kaiser Family Foundation, Johannesburg, South Africa, 2001.
[37] T. Shefer, A. Strebel, and D. Foster, "“'So women have to submit to that..." Discourses of power and violence in student's talk on heterosexual negotiation," South African Journal of Psychology, vol. 30, no. 2, pp. 11-19, 2000.

[38] B. M. Ahlberg, E. Jylkäs, and I. Krantz, "Gendered construction of sexual risks: implications for safer sex among young people in Kenya and Sweden," Reproductive Health Matters, vol. 9, no. 17, pp. 26-36, 2001.

[39] J. W. Gibson and A. Brown, Working with Qualitative Data, Sage, London, UK, 2009.

[40] C. Marshall and Rossman, Designing Qualitative Research, Sage, London, UK, 4th edition, 2006.

[41] D. Patel, "Evaluation of Kuwadzana, Parkridge-Fontainebleau. Low-Income Shelter Project Phase 1: evaluation of secondary sources of data," report prepared for submission to USAID, Harare, mimeo, June 1985.

[42] D. Potts and C. C. Mutambirwa, "High-density housing in Harare: commodification and overcrowding," Third World Planning Review, vol. 13, no. 1, pp. 1-25, 1991.

[43] Institute of Environmental Studies, Household Urban Waste Management Report, I. E.S Publications, Harare, Zimbabwe, 2012.

[44] M. N. Marshall, “The key informant technique," Family Practice, vol. 13, no. 1, pp. 92-97, 1996.

[45] G. T. Lie, "Ethical Dilemmas in Adolescent Reproductive Health Promotion," in Klepp, 2008.

[46] R. W. Connell, Men and Masculinities, Polity Press, Cambridge, UK, 1998.

[47] K. Ratele, "Male sexualities and masculinities," in Sexualities in Africa: A Reader, S. Tamale, Ed., pp. 399-419, 2011.

[48] M. Silberschimdt, "Masculinities, sexuality and socio-economic change in rural and urban East Africa," in Sexualities in Africa: A Reader, S. Tamale, Ed., pp. 233-248, 2011.

[49] R. Pattman, “'Boys and girls should not be too close”: sexuality, the identities of African boys and girls and HIV/AIDS education," Sexualities, vol. 8, no. 4, pp. 497-516, 2005.

[50] K. Rivers and P. Aggleton, Adolescent Sexuality, Gender and the HIV Epidemic, Gender and the HIV Epidemic, UNDP HIV and Development Programme, New York, NY, USA, 1999.

[51] G. Valentine, "Exploring children and young people's narratives of identity," Geoforum, vol. 31, no. 2, pp. 257-267, 2000.

[52] G. Van den Bergh, "From initiation rituals to AIDS education: entering adulthood at the turn of the millennium," in Promoting Adolescent Sexual and Reproductive Health in East and Southern Africa, K.-I. Klepp, A.-J. Flisher, and S. F. Kaaya, Eds., pp. 99116, The Nordic Africa Institute, Uppsala, Sweden, 2008. 

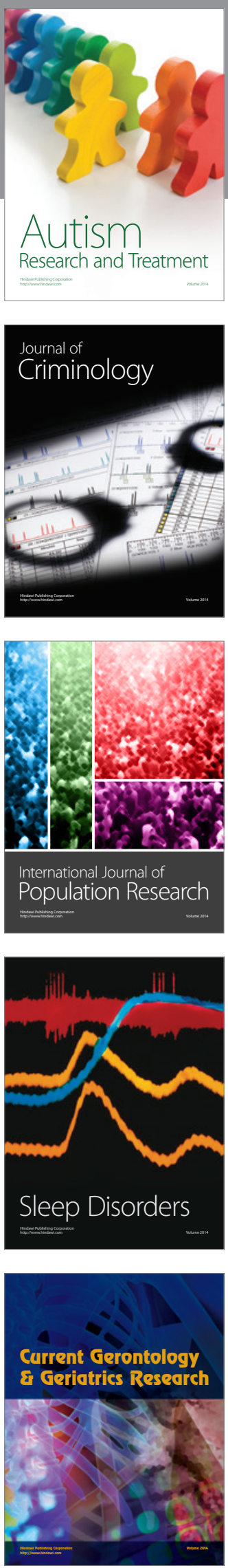
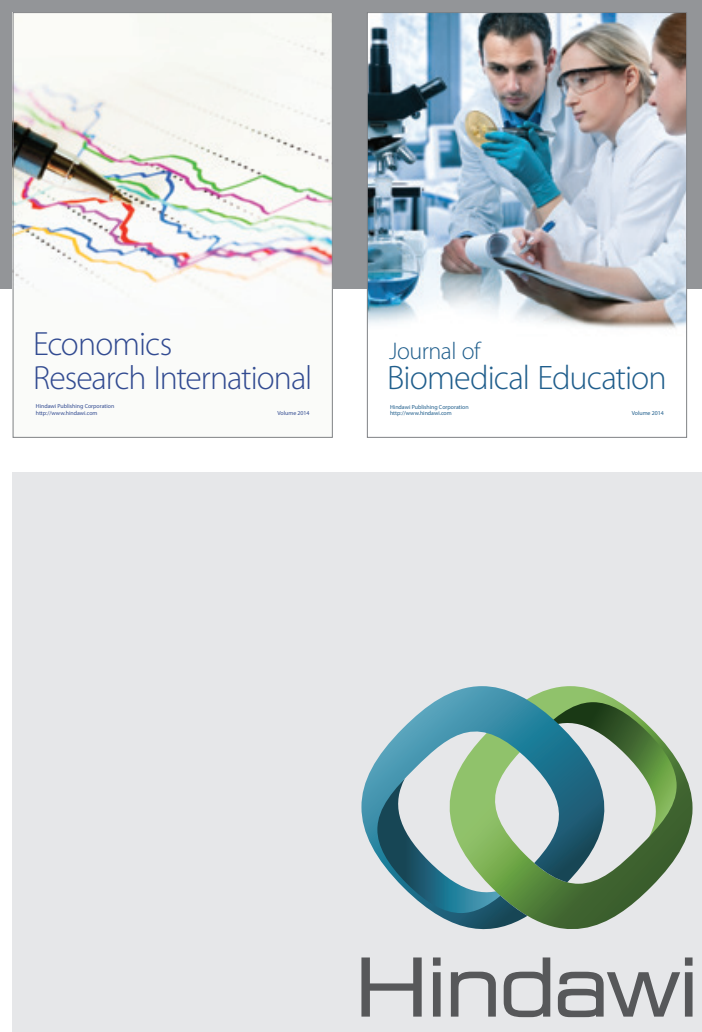

Submit your manuscripts at

http://www.hindawi.com
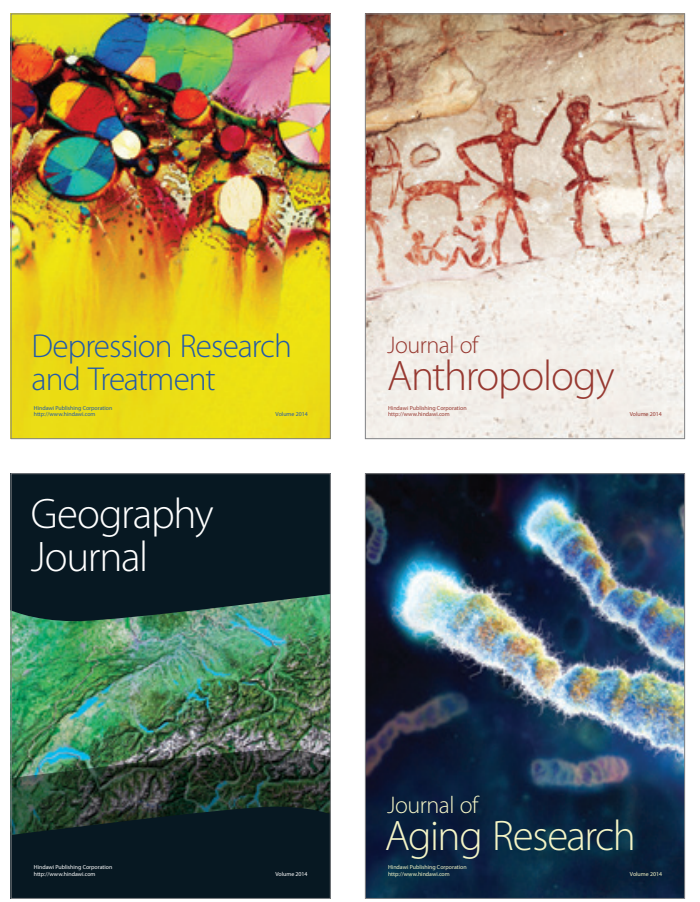
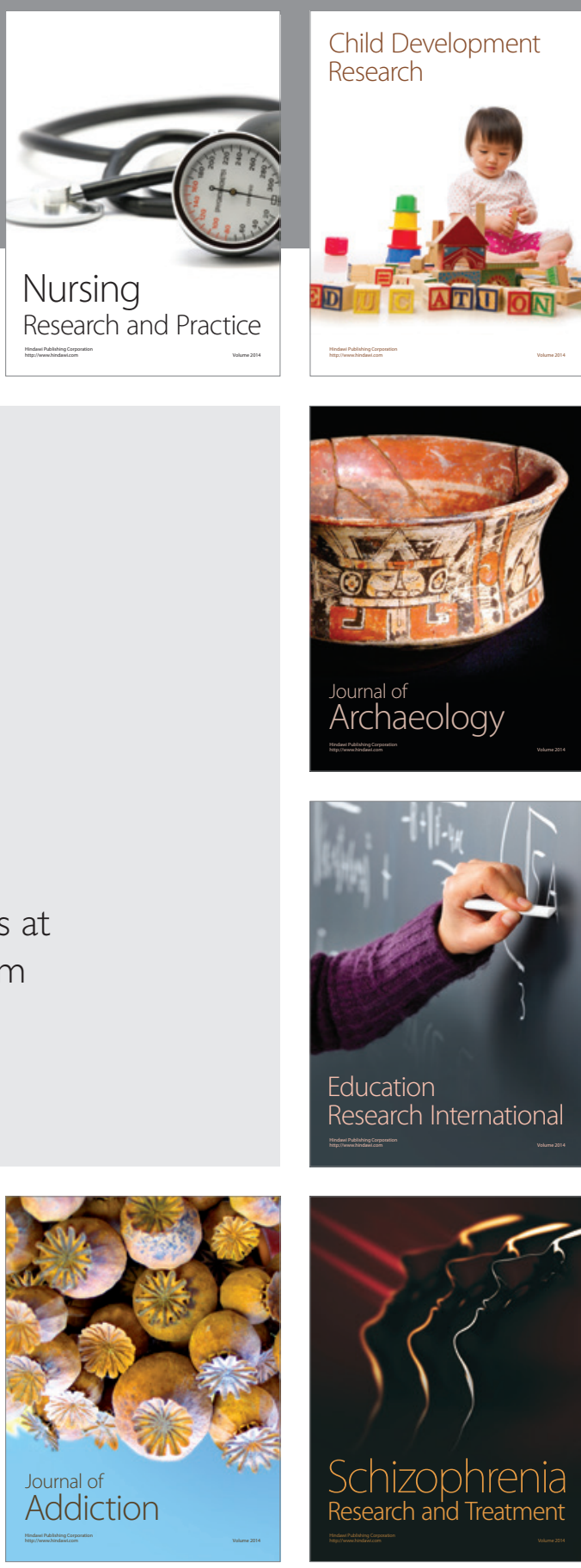

(D)
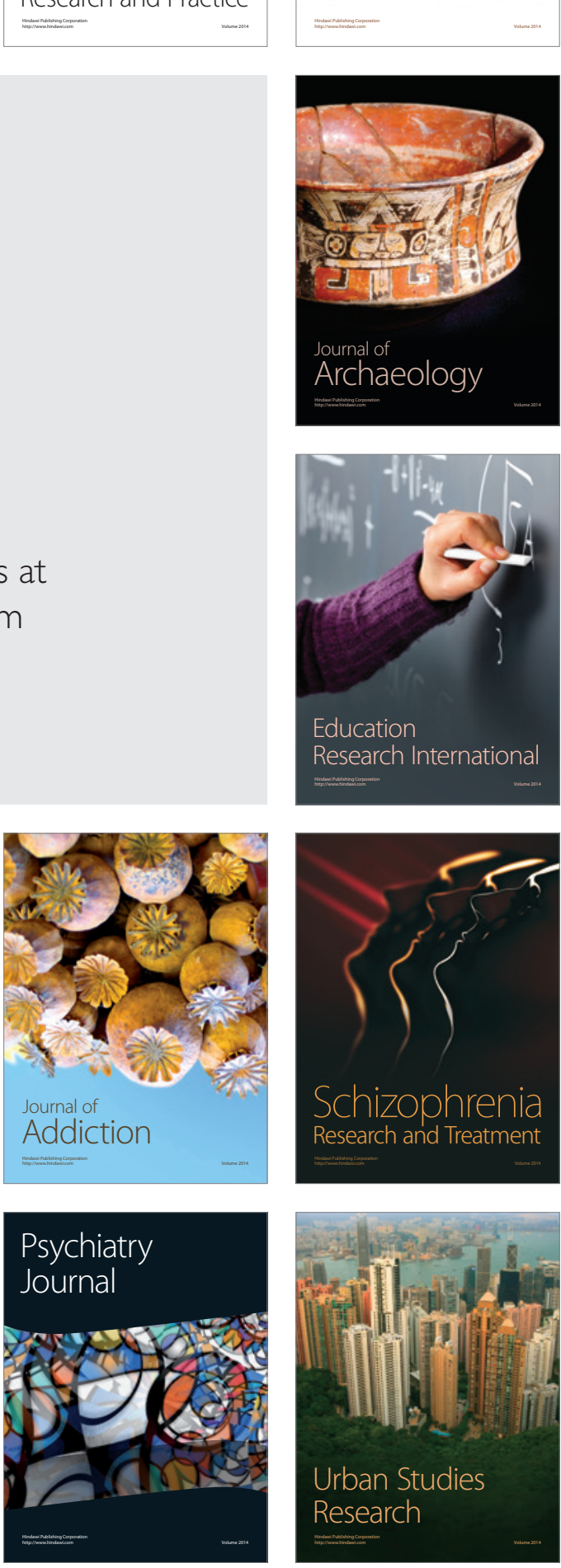